\title{
Anatomy of the fasciocutaneous branches of the first and second perforators arteries in the posterior thigh area
}

\author{
José Augusto Calil MD, Lydia Masako Ferreira MD PhD, José Laredo Filho MD PhD \\ Plastic Surgery, Federal University of São Paulo - Paulista School of Medicine, São Paulo, Brazil
}

\section{JA Calil, LM Ferreira, JL Filho. Anatomy of the fasciocutaneous branches of the first and second perforators arteries in the posterior thigh area. Can J Plast Surg 1998;6(3):155-158.}

The anatomy of the fasciocutaneous branches of the first and second perforators were studied to help elaborate a flap for use in the reconstruction of the gluteal and perineal regions. After dissecting 40 thighs in fresh cadavers, it was found that the fasciocutaneous branches of the first and second perforators were $1.21 \mathrm{~mm}$ and $1.01 \mathrm{~mm}$ in diameter, respectively. The distances from the first and second perforators to the greater trochanter of the femur were $6.23 \mathrm{~cm}$ and $12.19 \mathrm{~cm}$, respectively. The cutaneous area nourished by each one of the arteries was evaluated through the injection of dye.

Key Words: Skin blood supply, Surgical flaps, Thigh anatomy, Thigh histology

\section{Anatomie des branches fasciocutanées de la première et de la deuxième artères perforantes de la région} postérieure de la cuisse

RÉSUMÉ : L'anatomie des branches fasciocutanées de la première et de la deuxième artères perforantes a été étudiée dans le but d'élaborer un modèle de lambeau à utiliser dans la reconstruction des régions glutéale et périnéale. Après avoir disséqué 40 cuisses de cadavres frais, on a découvert que les branches fasciocutanées de la première et de la deuxième perforantes étaient respectivement de 1,21 $\mathrm{mm}$ et de $1,01 \mathrm{~mm}$ de diamètre. Les distances entre la première et la deuxième artères perforantes par rapport au grand trochanter du fémur étaient respectivement de $6,23 \mathrm{~cm}$ et de $12,19 \mathrm{~cm}$. La région cutanée irriguée par chacune de ces artères a été évaluée par injection de colorant.

$\mathrm{T}$ he pelvic and gluteal regions can be subjected to broad injuries with bone exposure that requires the use of flaps for their repair (1). The most frequent etiology is pressure sores, although infections, trauma and tumoural exeresis may also lead to extensive skin loss in that region $(2,3)$.

The reconstruction of these areas not only requires cutaneous coverage, but also demands flaps that resist pressure, provide sensibility whenever possible, preserve muscular functionality and produce less possible morbidity to the donor area (1).

The gluteal and posterior thigh regions are well irrigated, allowing the development of a variety of musculofasciocutaneous and fasciocutaneous flaps for wound closure. One usual option is the musculofasciocutaneous flap; it is based

Correspondence and reprints: Dr José Augusto Calil, Alameda Casa Branca, 962 apto 15-B, 01408-000 - Cerqueira Cesar, São Paulo-SP, Brazil. Telephone 011-280-9224, fax 011-571-6579, e-mail jacmmc@uol.com.br on the gluteus maximus and on the thigh posterior muscles because of their good blood supply, thick fatty padding and resistance to infection (3).

The fasciocutaneous flap, conceived by Pontén (4) in 1981, became a great repair option, lacking the disadvantage of compromising muscular functions. During the 1980s, several authors started to investigate the fasciocutaneous blood supply of various body segments (5-10). According to some authors $(2,11-15)$, the principal pedicle of the fasciocutaneous flap of the back side of thigh is the inferior gluteal artery fasciocutaneous branch; according to others $(3,5,16)$, the dominant pedicle is the first and second perforators. One author, Hallock (17), maintained that there is a wide range of regional vascular variation and that this flap is nourished by the fascial plexus without a predominant source.

The purpose of this study was to conduct an anatomical analysis of the fasciocutaneous branches of the first and second perforators to aid in the planning of gluteal and perineal region reconstructions; to focus on the localization, di- 


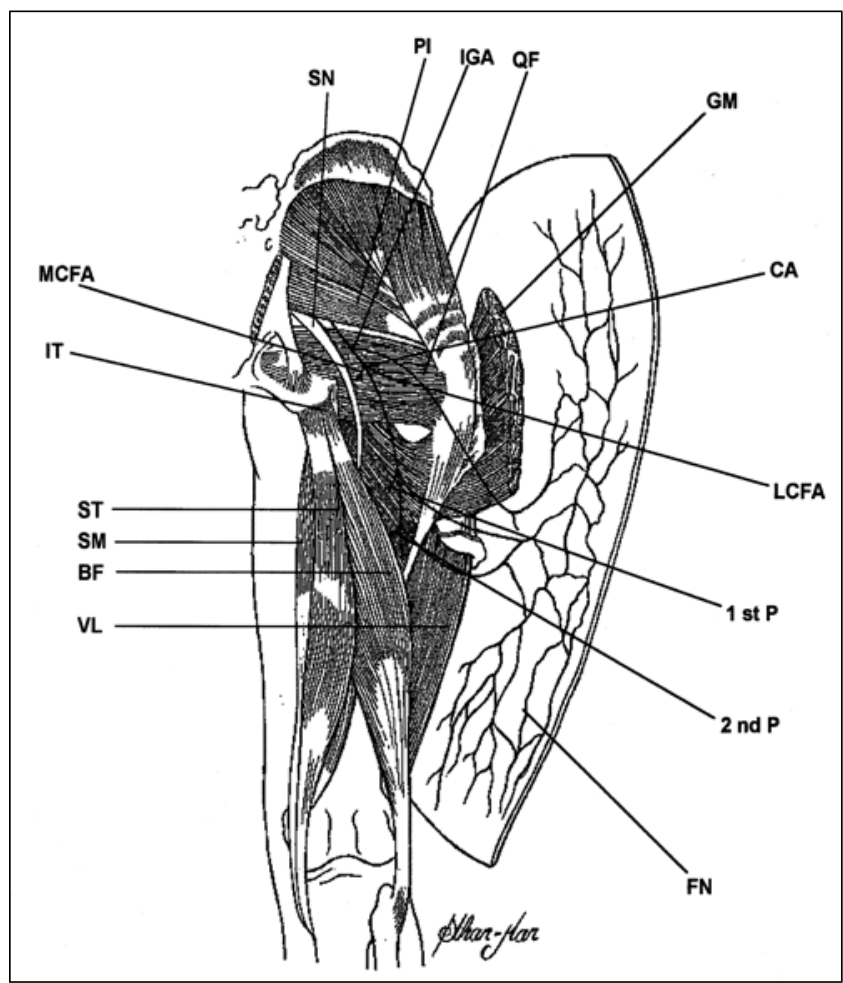

Figure 1) Schematic drawing of the gluteal and posterior thigh region. The skin, subcutaneous tissue and fascia lata were dissected from medial to lateral. Gluteus maximus muscle (GM) has been transected to show the underlying anatomy. BF Biceps femoris muscle; CA Cruciate anastomose; FN Fasciocutaneous network; IGA Inferior gluteal artery; IT Ischial tuberosity; LCFA Lateral circumflex femoral artery; MCFA Medial circumflex femoral artery; PI Piriform muscle; QF Quadratus femoris muscle; SM Semimembranous muscle; SN Sciatic nerve; ST Semitendinous muscle; VL Vastus lateralis; 1 st P First perforator artery; 2 nd $P$ Second perforator artery

ameter, skin territory and subcutaneous network supplied by each one of these arteries; and to use the flap with confidence.

\section{MATERIALS AND METHODS}

Twenty fresh adult cadavers (40 lower limbs) were used. The limits of the dissected area were marked out as a horizontal line crossing the medium point between the posterior superior iliac spine and the coccyx extremity superiorly; a horizontal line crossing the tibiale inferiorly; and a line joining the lateral condile of the tibia and the greater trochanter of the femur laterally, and posterior border of gracilis muscle medially.

Dissection of the fasciocutaneous flap included the posterior cutaneous nerve of the thigh and the artery, from the inferior to the superior boundaries of the marked area, onto the inferior edge of the gluteus maximus muscle. Registration was done of the first and second perforators' diameter at their penetration level in the fascia lata and of their distance from the greater trochanter of the femur.

To evaluate the cutaneous area nourished by the first and second perforators, methylene blue or bright green dyes were injected into each artery.

\section{First perforator artery}

The first perforator artery pierces the adductor magnus and penetrates the back thigh medial to the lesser trochanter of the femur, near the insertion of the gluteus maximus. From it, muscular branches extend to the gluteus maximus and to the thigh posterior muscles; anastomotic branches and fasciocutaneous branches extend to the skin and to the overlaying cutaneous network (Figure 1). The fasciocutaneous branch diameter, as it pierced the facia lata, ranged from 0.8 to $1.9 \mathrm{~mm}$ (average $1.21 \mathrm{~mm}$ ).

The point where the fasciocutaneous branch pierced the fascia ranged from 3.0 to $11.0 \mathrm{~cm}$ from the greater trochanter of the femur (average $6.23 \mathrm{~cm}$ ).

\section{Second perforator artery}

The second perforator artery pierces the adductor magnus on the posterior side of the thigh through the septum between the vastus lateralis muscle and biceps femoris. It gives off muscular branches, anastomotic branches and a fasciocutaneous branch (Figure 1). The diameter of the fasciocutaneous branch as it penetrates the fascia lata ranged from 0.5 to $1.7 \mathrm{~mm}$ (average $1.01 \mathrm{~mm}$ ). The distance between the penetration point in the fascia of the fasciocutaneous branch and the greater trochanter of the femur ranged from 8.0 to $18.0 \mathrm{~cm}$ (average $12.19 \mathrm{~cm}$ ).

\section{Stained cutaneous area}

The dye injection into the first perforator flushed the areas, as shown in Figures 2 and 3. The area stained by the second perforator is shown in Figures 4 and 5.

\section{DISCUSSION}

Hurwitz (12) was the first author to use a musculofasciocutaneous flap raised from the posterior side of the thigh, pedicled with the fasciocutaneous branch of the inferior gluteal artery for broad pelvic injuries repair.

Rubin et al (3) described how the first perforator pierces the adductor magnus between 2 and $4 \mathrm{~cm}$ below the ischial tuberosity and gives off, first, muscular branches to the distal part of the gluteus maximus and back thigh muscles; second, an anastomotic branch towards the cruciformis anastomosis; and third, a fasciocutaneous branch to the superolateral skin of the thigh, with diameters ranging from 1 to $2 \mathrm{~mm}$. These observations are in agreement with the data reported in this study. Rubin and coworkers (3) also maintain that the second perforator's distance from the ischial tuberosity is 4.0 to $6.0 \mathrm{~cm}$, and that it gives off one or two fasciocutaneous branches to the skin of the midthird of the thigh, with diameters ranging between 1.0 and $2.0 \mathrm{~mm}$.

In our study, the diameter of the second perforator ranged from 0.5 to $1.7 \mathrm{~mm}$. It was located inferior to the greater trochanter of the femur and at a distance of 8 to $18 \mathrm{~cm}$ (average $12.19 \mathrm{~cm})$.

Rubin et al (3) injected methylene blue and bright green dye in the trunk of the inferior gluteal artery of six thighs and in each thigh's perforator (by anterior access to the thigh). 


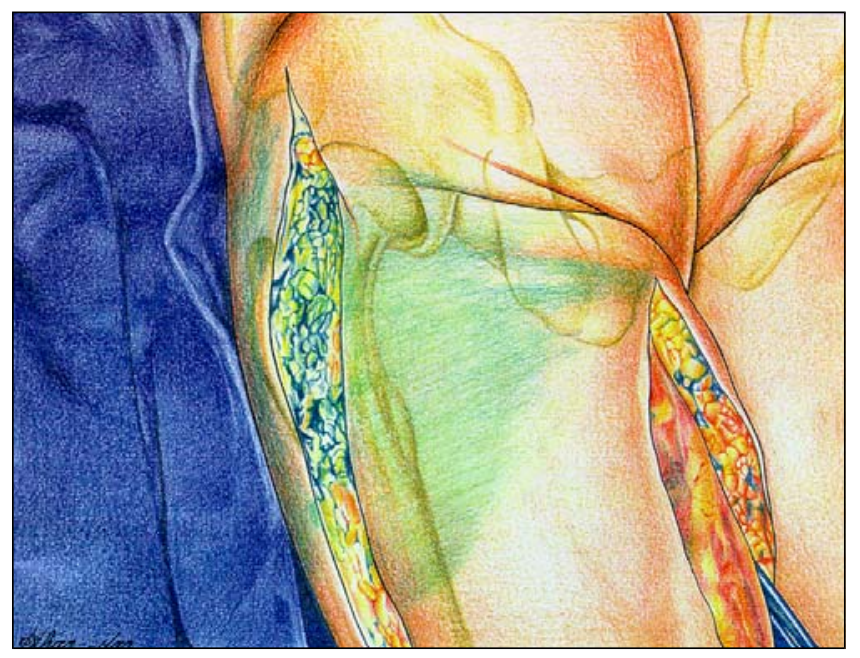

Figure 2) Schematic drawing of the first perforator coloured area

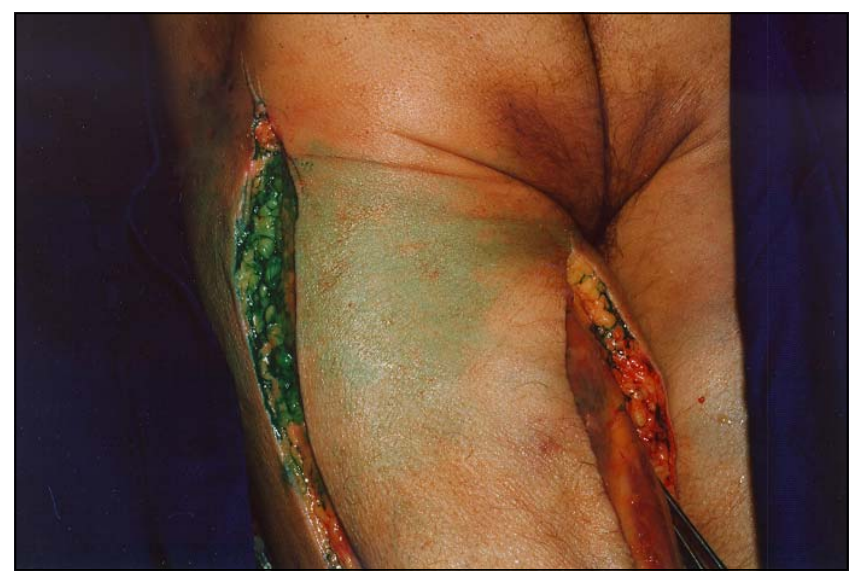

Figure 3) Skin area stained by the first perforator artery

They found that the cutaneous vascular territory of the inferior gluteal artery was limited to the skin of the inferior gluteal region. The first and second perforators perfused the skin of the superolateral and midinferolateral regions of the thigh. The stained vascular territories were evident in a few intersectional areas between them.

An intersectional area was found in the midlateral region, between the first and second perforators, suggesting the existence of a common nutrition area shared by the fasciocutaneous branches with connections between their vascular networks.

Taylor and Palmer (18) defined the angiosome as a composed tissue block that is nourished by a source artery. The artery that supplies the blocks accounts for the blood supply to the skin and underlying structures. They found the presence of two angiosomes in the back thigh: the inferior gluteus and the deep femoral. They also maintained that, most of the time, a flap based on a vessel pertaining to one angiosome can safely capture the tissues of the neighbouring angiosome, on a clinical basis. This ability is presumably due to the pressure gradient that may occur when blood flows across the small vessels, extending communication to the adjacent arterial territories.

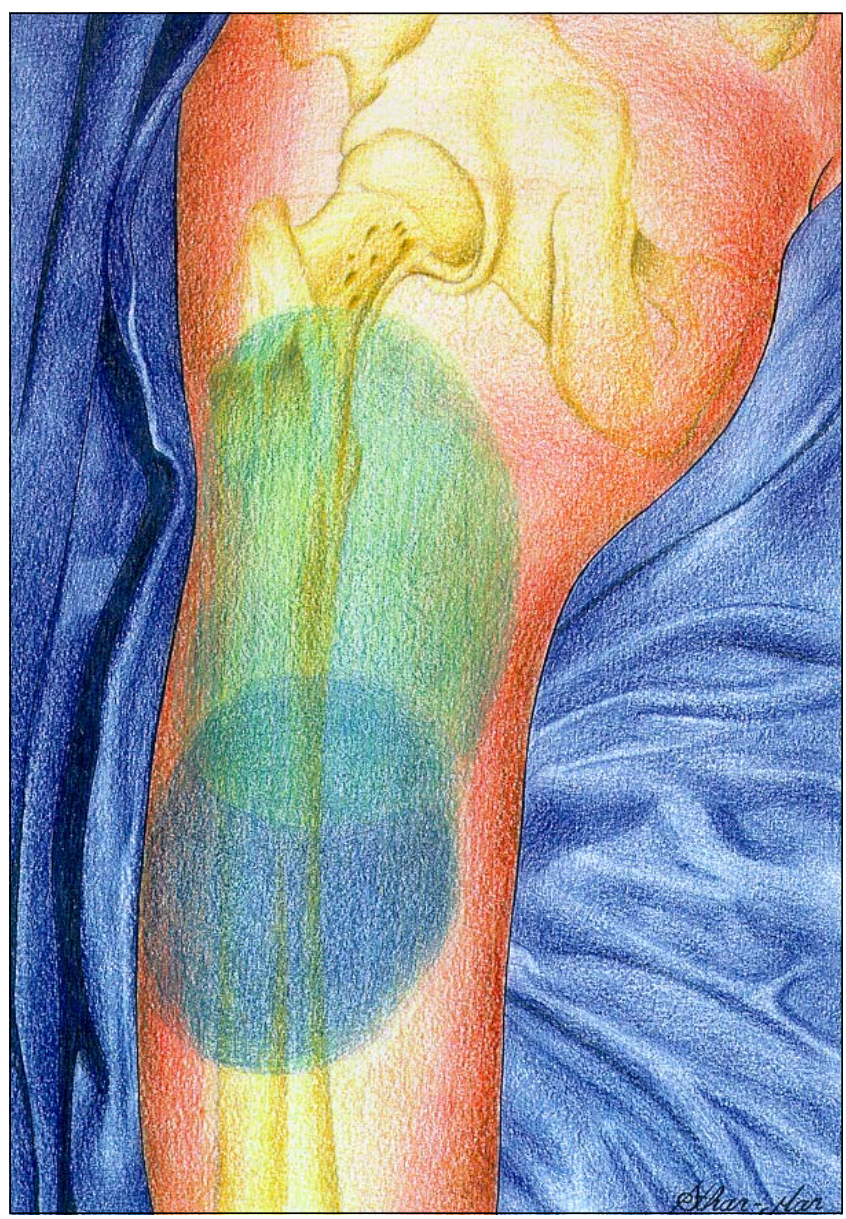

Figure 4) Schematic drawing of the first and second perforators coloured areas, in green and blue, respectively

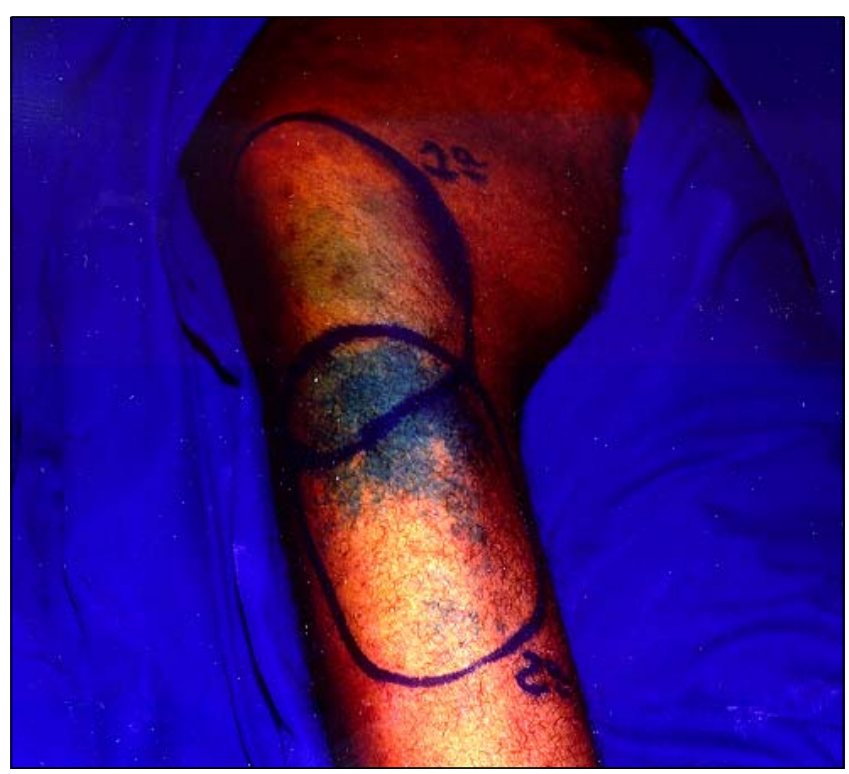

Figure 5) Skin area stained by the first and second perforators arteries, in green and blue, respectively

According to Ramirez (19), the whole skin of the posterior thigh, from the iliotibial tract to the medial intermuscular septum, can be included in a flap pedicled with the gluteus 
maximus muscle. The survival of the skin of the posterior thigh depends on the intercommunication among musculocutaneous perforators of the superior gluteal, inferior gluteal and medial circumflex arteries of the thigh and on the first perforator, which form a rich fascial and subdermal web.

Ramirez et al (20) maintained that the whole gluteus maximus may survive pedicled in the cruciformis anastomosis alone because it is formed by the branches of the inferior gluteal, first perforators, and the lateral and medial circumflex arteries of the thigh.

The first perforator gives off ascending branches that form anastomosis with descending branches that nourish the thigh posterior skin. Therefore, the posterolateral region of the thigh is nourished by a rich vascular network formed by the first perforator, corresponding to the intersection of the cutaneous surface stained by the inferior gluteal and the first perforators.

The long and well-defined cutaneous branch of the inferior gluteal artery, which runs with the posterior cutaneous nerve of the thigh, is substituted in many occasions with a fascial plexus receiving a plentiful contribution from the first perforator. This explains the extraordinary viability of this flap, especially when the cruciformis anastomosis is not totally damaged.

The back of the thigh may be used in trochanter and ischial pressure sore repair by raising fasciocutaneous $\mathrm{V}-\mathrm{Y}$ advancement flaps, pedicled laterally with the first and second perforators; this procedure is possible because a large part of

\section{REFERENCES}

1. Rosen JM, Mo ST, Liu A. Experience with the island inferior gluteal thigh flap compared with other local flaps for reconstruction of the pelvic area. Ann Plast Surg 1990;24:498-509.

2. Achauer BM, Braly P, Berman ML, Disaia PJ. Immediate vaginal reconstruction following resection for malignancy using the gluteal thigh flap. Gynecol Oncol 1984;19:79-89.

3. Rubin JA, Whetzel TP, Stevenson TR. The posterior thigh fasciocutaneous flap: Vascular anatomy and clinical application. Plast Reconstr Surg 1995;95:1228-39.

4. Pontén B. The fasciocutaneous flap: its use in soft tissue defects of lower leg. Br J Plast Surg 1981;34:215-20.

5. Cormack GC, Lamberty BGH. The blood supply of thigh the skin. Plast Reconstr Surg 1985;75:342-54.

6. Ferreira LM. Contribuição ao estudo da irrigação da fáscia da região posterior da perna. São Paulo: Tese-Doutorado-Escola Paulista de Medicina, 1985.

7. Ferreira LM, Andrews JM, Laredo Filho J. Retalho fasciocutâneo da base distal: estudo anatômico e aplicação clínica nas lesões do terço inferior da perna e tornozelo. Rev Bras Orthop 1987;22:125-8.

8. Ferreira LM, Andrews JM, Laredo Filho J, Ramos RR. Retalho fasciocutâneo axial na reparação das perdas de substância da perna. Folha Méd 1986;93:261-3.

9. Haertsch PA. The blood supply to skin of the leg: a post-mortem investigation. Br J Plast Surg 1981;34:470-7.

10. Tolfhurst DE, Haeseker B. Fasciocutaneous flaps in axillary region. Br J Plast Surg 1982;35:430-5.

11. Achauer BM, Turpin IM, Furnas DW. Gluteal thigh flap in the skin is nourished by these arteries, as shown by the stained area demonstrated in this study. Rubin et al (3) reported that they successfully used this flap in 24 cases. Their report points out the technique's advantages, such as the large dimensions of the flap, preservation of adjacent cutaneous territories, possibility of readvancement of the flap, easy donor-site closure and preservation of the underlying muscles.

\section{CONCLUSIONS}

From our study of the fasciocutaneous branches of the first and second perforators, we conclude the following points.

- The first perforator is situated, on average, $6.23 \mathrm{~cm}$ from the greater trochanter of the femur and has an average diameter of $1.21 \mathrm{~mm}$.

- The average diameter of the second perforator is $1.01 \mathrm{~mm}$ and is situated, on average, $12.19 \mathrm{~cm}$ from the greater trochanter of the femur.

- A skin region nourished by the first perforator enables the safe development of a fasciocutaneous flap, which would extend over the midlateral region, the proximal portion of the midmedial region and distal portions of the superolateral and superomedial regions.

- The cutaneous area nourished by the second perforator enables the safe development of a fasciocutaneous flap, including the distal portions of the midlateral, midmedial regions and proximal portion of the inferolateral regions.

reconstruction of complex pelvic wounds. Arch Surg 1983;118:18-22.

12. Hurwitz DJ. Closure of a large defect of the pelvic cavity by an extended compound myocutaneous flap based on the inferior gluteal artery. Br J Plast Surg 1980;33:256-61.

13. Hurwitz DJ, Swartz WM, Mathes SJ. The gluteal thigh flap: A reliable, sensate flap for the closure of buttock and perineal wounds. Plast Reconstr Surg 1981;68:521-32.

14. Hurwitz DJ, Walton RL. Closure of chronic wounds of the perineal and sacral regions using the gluteal thigh flap. Ann Plast Surg 1982;8:375-86.

15. Komuro Y, Takato T, Ueda K, Harii K. Experience with U-shaped gluteal thigh flaps for reconstruction of radionecrosis in the sacral region. Ann Plast Surg 1993;31:475-8.

16. Calil JA. Anatomia dos ramos fascio-cuâneos das artérias glútea inferior primeira e segunda perfurantes. São Paulo: Tese-Mestrado Universidade Federal de São Paulo - Escola Paulista de Medicine, 1996.

17. Hallock GG. The random upper posterior thigh fasciocutaneous flap. Ann Plast Surg 1994;32:367-71.

18. Taylor GI, Palmer JH. The vascular territories (angiosomes) of the body: experimental study and clinical applications. Br J Plast Surg 1987;40:113-41.

19. Ramirez OM. The distal gluteus maximus advancement musculocutaneous flap for coverage of trochanteric pressure sores. Ann Plast Surg 1987;18:295-302.

20. Ramirez OM, Hurwitz DJ, Futrell JW. The expansive gluteus maximus flap. Plast Reconstr Surg 1984;74:757-68. 